\section{Commentary: A complex problem seeking the ideal solution}

\author{
Daniel Silverberg, MD, ${ }^{\mathrm{a}}$ and Ehud Raanani, $\mathrm{MD}^{\mathrm{b}}$
}

The treatment of acute type B aortic dissection (TBAD) has been evolving continuously over the last 2 decades. While the majority of acute TBADs can be managed medically, complicated TBAD, presenting with visceral malperfusion, refractory pain or aortic rupture, frequently requires urgent surgical intervention. Several therapeutic options have been described. Thoracic endovascular aortic repair (TEVAR) has emerged as the dominant strategy for resolving malperfusion for complicated $\mathrm{TBAD}^{1}$ and is effective in covering the proximal entry tear in the majority of cases. It does, however, carry the risk of persistent perfusion of the false lumen (FL) through additional tears in the thoracoabdominal aorta, and might not resolve the visceral malperfusion. Indeed, in the presented manuscript, the visceral arteries remained occluded after placement of a proximal endograft. Another endovascular option is to percutaneously create a fenestration in the dissection flap, combined with visceral artery stenting, to equalize the blood pressure between the FL and the true lumen (TL), thereby permitting flow between the 2 lumens. ${ }^{2}$ A third option is to perform TEVAR followed by bare stent implantation in the thoracoabdominal aorta, also known as the PETTICOAT technique. This option has the added value of promoting TL expansion and malperfusion relief; it has been shown to improve TL reexpansion of the distal aorta and improve end-organ perfusion. ${ }^{3}$

From the a Endovascular Surgery Service, Department of Vascular Surgery, Sheba Medical Center, Tel Hashomer, Israel; and ${ }^{\mathrm{b}}$ Cardiothoracic Surgery, Leviev Cardiothoracic and Vascular Center, The Sackler School of Medicine, Tel Aviv, Israel, Sheba Medical Center, Tel Hashomer, Israel.

Disclosures: The authors reported no conflicts of interest.

The Journal policy requires editors and reviewers to disclose conflicts of interest and to decline handling or reviewing manuscripts for which they may have a conflict of interest. The editors and reviewers of this article have no conflicts of interest.

Received for publication Aug 12, 2020; revisions received Aug 12, 2020; accepted for publication Aug 13, 2020; available ahead of print Aug 15, 2020.

Address for reprints: Ehud Raanani, MD, Cardiothoracic Surgery, Leviev Cardiothoracic and Vascular Center, Sheba Medical Center, Ramat Gan, Israel (E-mail: Ehud.Raanani@sheba.health.gov.il).

JTCVS Techniques 2020;3:66-7

2666-2507

Copyright (c) 2020 The Authors. Published by Elsevier Inc. on behalf of The American Association for Thoracic Surgery. This is an open access article under the CC BY-NCND license (http://creativecommons.org/licenses/by-nc-nd/4.0/).

https://doi.org/10.1016/j.xjtc.2020.08.028

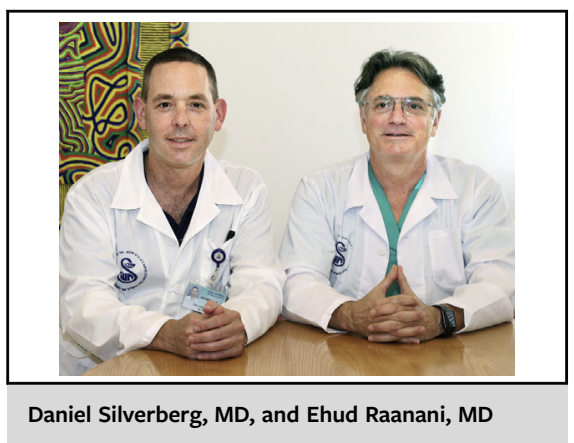

CENTRAL MESSAGE

Visceral malperfusion caused by acute type $A$ dissection can be treated with a variety of methods, and occasionally can be treated before proximal aortic repair.

In the current issue of the Journal, Preventza and colleagues ${ }^{4}$ present a creative solution for acute type A aortic dissection (TAAD) complicated with visceral malperfusion. Classic teaching dictates that patients with acute TAAD, even those suffering from visceral malperfusion, require initial open repair of the proximal aorta, assuming that stabilizing the TL through the aortic repair resolves organ malperfusion. However, in some cases, end-organ failure from malperfusion might be a more immediate life-threatening problem.

Moreover, it has been demonstrated that TAAD patients presenting with visceral malperfusion have significantly worse clinical outcomes after TAAD repair. ${ }^{5}$ Thus, treating the visceral malperfusion before treating the proximal aorta appears reasonable in certain clinical situations, particularly when the proximal dissection does not present an immediately life-threatening problem. This approach has been reported by Yang and colleagues ${ }^{6}$ in a series of 135 patients with visceral malperfusion treated upfront with endovascular reperfusion, followed by delayed open repair. In their experience, this sequence yielded a survival benefit compared with a proximal repair-first approach. Although this approach appears to be beneficial in certain clinical scenarios, it puts patients at risk for aortic rupture and tamponade while awaiting resolution of visceral malperfusion.

In our opinion, a key element in this debate lies in correctly predicting which patients with acute TAAD can tolerate distal treatment first followed by delayed open proximal aorta repair, compared to standard proximal 
repair first. Another option is a sequential approach with endovascular distal malperfusion treatment followed immediately by open proximal repair, preferably both performed in the same hybrid operating theater. Currently, there are insufficient data to resolve this debate, and each case should be evaluated ad hoc with all 3 options considered.

\section{References}

1. Alfson DB, Ham SW. Type B aortic dissections: current guidelines for treatment. Cardiol Clin. 2017;35:387-410.
2. Bertoglio L, Rinaldi E, Melissano G, Chiesa R. The PETTICOAT concept for endovascular treatment of type B aortic dissection. J Cardiovasc Surg (Torino). 2019;60:91-9.

3. Kamman AV, Yang B, Kim KM, Williams DM, Michael Deeb G, Patel HJ Visceral malperfusion in aortic dissection: the Michigan experience. Semin Thorac Cardiovasc Surg. 2017:29:173-8.

4. Preventza O, Oluyinka OO II, Chatterjee S, Le Huu A, Coselli JS. Provisional extension to induce complete attachment of an endovascular repair for acute type A aortic dissection with visceral malperfusion. J Thorac Cardiovasc Surg Tech. 2020;3:61-3.

5. Elsayed RS, Cohen RG, Fleischman F, Bowdish ME. Acute type A aortic dissection. Cardiol Clin. 2017;35:331-45.

6. Yang B, Rosati CM, Norton EL, Kim KM, Khaja MS, Dasika N, et al. Endovascular fenestration/stenting first followed by delayed open aortic repair for acute type A aortic dissection with malperfusion syndrome. Circulation. 2018;138:2091-103. 